\title{
POLÍTICAS PARA EDUCAÇÃO INFANTIL E PROMOÇÃO DA IGUALDADE RACIAL: ANÂLISES A PARTIR DE MATERIAIS PRODUZIDOS POR SISTEMAS PRIVADOS DE ENSINO E ADERIDOS POR REDES PÚBLICAS
}

\author{
POLICIES FOR CHILDREN EDUCATION AND RACIAL RELATIONS: ANALYZES \\ FROM MATERIALS PRODUCED BY PRIVATE EDUCATION SYSTEMS AND \\ ADHERED TO BY PUBLIC NETWORKS
}

\author{
Thaís Regina de Carvalho \\ Doutora em educação \\ Universidade Federal de Goiás - UFG \\ Goiânia, Goiás - Brasil \\ decarvalho@ufg.br
}

Resumo: O presente artigo abordará alguns apontamentos sobre as políticas para a educação infantil, com foco na inserção de sistemas privados de ensino nessa etapa da educação básica. Para isso, discutiremos sobre a adesão, o aumento e a permanência de sistemas privados de ensino em redes municipais de educação infantil. Ancorando-nos no artigo 26-A da Lei de Diretrizes e Bases da Educação, analisaremos imagens de dez livros didáticos com o intuito de verificar as formas como as personagens negras e brancas estão representadas. A coleta de dados foi formada a partir de análises de conteúdo. As reflexões estão embasadas nos estudos críticos sobre relações raciais no Brasil, educação infantil e adoção de sistemas privados de ensino. Os resultados retratam a reprodução das características das relações raciais brasileiras.

Palavras-chave: livros didáticos; políticas para educação infantil; relações raciais; sistema privado de ensino.

\begin{abstract}
This article will debate some notes on policies for early childhood education, focusing on the insertion of private education systems in this stage of Brazilian basic education. For this, we will discuss about the adhesion, increase and permanence of private education systems in municipal early childhood education. Anchoring in article 26-A of the Law of Guidelines and Bases of Education, we will analyze images of ten textbooks, in order to verify the ways in which black and white characters are represented. Data collection took place through documentary and content analysis. The reflections are based on critical studies on race relations in Brazil, early childhood education and adoption of private education systems. The results show the reproduction of the characteristics of Brazilian race relations.
\end{abstract}

Keywords: textbooks; policies for early childhood education; race relations; private teaching system.

\section{Para citar - (ABNT NBR 6023:2018)}

CARVALHO, Thaís Regina de. Políticas para educação infantil e promoção da igualdade racial: análises a partir de materiais produzidos por sistemas privados de ensino e aderidos por redes públicas. Eccos - Revista Científica, São Paulo, n. 58, p. 1-18, e10745, jul./set. 2021. Disponível em: https://doi.org/10.5585/eccos.n58.10745. 


\section{Considerações iniciais}

A adoção de sistemas privados de ensino por parte de redes públicas de educação infantil vem se configurando como uma prática recorrente em diversos municípios brasileiros. Em acordo com Adrião et al. (2012), os sistemas privados de ensino (SPE) podem ser caracterizados como:

[...] "cesta de serviços e produtos" oferecida aos municípios-clientes, material didático conhecido como "material apostilado", distribuído aos estudantes e aos professores em versões distintas. Além disso, as empresas oferecem assessorias que envolvem procedimentos de avaliação sobre o uso adequado dos materiais, "treinamentos" a docentes e acesso a portais com instruções detalhadas sobre sua utilização. A empresa privada oferece ao setor público, na verdade, um programa de ensino que incide sobre a organização dos tempos e rotinas de trabalho nas unidades escolares, que constituem formas de controle sobre este trabalho. (ADRIÃO et al., 2012, p. 538).

Perante essas informações, cabe refletir sobre o fato de que: “[...] A educação infantil tem se tornado um espaço lucrativo para as empresas." (ADRIÃO; BORGHI; DOMICIANO, 2010, p. 292). Tendo em vista tal informação, é possível pontuar o aumento da adesão desses sistemas por parte das redes municipais de educação.

A partir desse dado, suscitam questionamentos a partir das relações entre a inserção do poder privado em âmbito público, isto é, como o sistema privado de ensino, em certa medida, vem definindo algumas políticas públicas educacionais. Nessa direção, Adrião, Damaso e Galzerano (2013, p. 438) ressaltam as reflexões sobre: “[...] o papel que os grandes grupos empresariais vêm assumindo na definição da agenda educacional em âmbito global, com objetivo, nem sempre explícito, de ampliar ou criar mercados."

Seguindo essa perspectiva, salientamos os múltiplos movimentos das políticas e as possíveis complexidades dos processos de adoção desses sistemas, já que estes precisam contemplar determinados aspectos de dimensão pública (documentos orientadores, critérios, processos de licitação, entre outros) para ingressar nas redes municipais, as quais são integrantes de um sistema municipal ou estadual de educação tendo, portanto, que seguir determinadas normativas. Sendo assim, consideramos que, ao estudar as políticas de adesão aos sistemas privados de ensino, torna-se necessário considerar que elas estão imersas a diversos tensionamentos e relações que envolvem as disputas por poder, tanto nas redes públicas de educação quanto nos próprios sistemas.

Assim sendo, a escolha por estudar os materiais e ações dos sistemas privados de ensino se faz pertinente, principalmente ao considerarmos que eles afirmam cumprir as disposições dos documentos nacionais que buscam subsidiar as políticas e práticas pedagógicas. Portando, compreender os SPE envolve múltiplos aspectos. Para o presente artigo, elencamos como 
recorte as análises sobre a representação de personagens negras e brancas em imagens de dez livros didáticos pertencentes a três coleções direcionadas a crianças de zero a cinco anos de idade, a saber: uma destinada às redes públicas, outra às redes privadas e outra à rede editorial (pública e privada), ambas produzidas pela mesma editora. Diante disso, vale enfatizar que as problematizações sobre a diversidade étnico-racial não estão silenciadas nos documentos nacionais que buscam orientar as políticas e ações da educação infantil. Além disso, as disposições das "Diretrizes Curriculares Nacionais para a educação das relações étnico-raciais e para o ensino de história e cultura africana e afro-brasileira" - DCN's ERER (2004), assim como os diversos documentos que visam subsidiar os trabalhos com a temática, são direcionadas a todas as unidades de ensino, incluindo, portanto, todas as instituições da primeira etapa da educação básica, inclusive, as que adotam sistemas privados de ensino.

Ponderando esses apontamentos, as análises e debates que serão apresentados ao longo dessa produção se ancoram nos estudos críticos sobre relações raciais no Brasil (GOMES, 2012; PAIXÃO, 2013; SILVA, 2008), explicitando a compreensão das relações raciais enquanto um problema de toda a sociedade brasileira. Ademais, é relevante salientar o direito de todas as crianças em ter acesso aos conhecimentos referentes à história e cultura africana e afrobrasileira, independentemente do pertencimento étnico-racial e ambiente educativo que frequentam, pois:

Educar para a igualdade racial na Educação Infantil significa ter cuidado não só na escolha de livros, brinquedos, instrumentos, mas também cuidar dos aspectos estéticos, como a eleição dos materiais gráficos de comunicação e de decoração condizentes com a valorização da diversidade racial. A escolha dos materiais deve estar relacionada com sua capacidade para estimular, provocar determinado tipo de respostas e atividades. (BRASIL, 2012, p. 21).

Imersas/os às perspectivas expostas, o artigo apresentará um debate sobre as políticas para educação infantil, com ênfase para a adoção de SPE e em seguida problematizará aspectos presentes em algumas imagens tendo como foco as formas e estratégias para a representação de personagens negras e brancas.

\section{Educação infantil e a adoção de sistemas privados de ensino: alguns apontamentos}

Em meio a lutas, debates, embates e $\operatorname{conquistas}^{1}$, a década de 1990 se apresenta como um marco para a educação das crianças de zero a seis anos de idade. A partir desse período, a educação infantil passa a ser normatizada por meio da Constituição Federal de 1988 enquanto

\footnotetext{
${ }^{1}$ Entre os movimentos, é dado destaque para o Movimento de Mulheres que, devido ao aumento da presença feminina no mercado de trabalho, passa a reivindicar creches e pré-escolas.
} 
um dever do Estado, e logo em seguida regulamentada na Lei de Diretrizes e Bases da Educação Nacional (LDB/96).

Nunes (2006), ao abordar sobre os processos de construção das políticas públicas de atendimento à educação das crianças de zero a seis anos, enfatiza as particularidades e os contextos de cada região, bem como elenca alguns pontos que podem contribuir para a compreensão da institucionalização da educação infantil no Brasil. Esta, segundo a autora, desde a era Vargas (e se mantendo na década de 1960) era guiada por discursos higienistas e de saneamento, tendo a sua oferta concentrada em instituições públicas e filantrópicas. De acordo com Kuhlmann Jr. (2015), a partir dos anos 1960 as instituições de educação infantil passaram a ser mais reconhecidas. Já na década de 1970, com fortes influências das agências internacionais e por programas realizados nos Estados Unidos e na Europa, as políticas para a educação infantil foram marcadas pela educação compensatória. Ou seja, disseminavam o ideal de compensação às carências culturais, linguísticas e afetivas das crianças com menor poder aquisitivo. Além disso, nessa década, a concepção de pré-escola enquanto antecipação para o ensino fundamental, como forma de "salvação" para o fracasso escolar também era propagada. A respeito dessas políticas, Rosemberg (2011) nos apresenta a seguinte reflexão:

A opção brasileira nos anos 1970 por expandir a educação infantil por meio de modelo não-formal apoiado nos baixos salários de professoras leigas, prioritariamente para região Nordeste, diferenciou o padrão de oferta do atendimento, não só quanto ao desenvolvimento regional mas, também aos segmentos raciais. Esses programas a baixo investimento do Estado atingiram principalmente as crianças negras, pobres, principais usuárias de creches públicas e conveniadas. (ROSEMBERG, 2011, p. 18).

Esse fato é complexo, pois demarca as desigualdades na oferta de uma educação infantil de qualidade. Em acordo com Nunes (2006), contando com a atuação dos movimentos sociais, nas décadas de 1980 e 1990 as propostas passam a ganhar outros entornos, focando, principalmente, no direito à educação das crianças pequenas e no dever de oferta por parte do Estado. O ano de 1990 também é reconhecido pela elaboração dos documentos que reafirmam a educação infantil enquanto um direto da criança, entre eles, o Estatuto da Criança e Adolescente (ECA/1990) e a LDB (1996).

A partir do ano 2000, algumas concepções vão se consolidando ${ }^{2}$ e a educação infantil: “[...] passa a ser vista como uma necessidade contemporânea." (NUNES, 2006, p. 2). Nessa direção, a autora salienta a importância do papel dos movimentos sociais e dos estudos da área

\footnotetext{
${ }^{2}$ As informações apresentadas consideram os movimentos das políticas, não disseminando, portanto, a ideia de que, ao surgirem novas tendências e concepções, as antigas simplesmente são eliminadas. Pelo contrário, conforme os estudos, observamos que diferentes práticas ocorrem concomitantemente.
} 
no processo de construção da concepção dos elementos necessários para a realização das ações e políticas. Entre eles, Nunes (2006) relata que a educação infantil,

[...] (I) engloba o educar e cuidar da criança de 0 a 6 anos de forma integrada e indissociável; (II) não é frequentado por crianças com mais de sete anos de idade; (III) é concebido como um serviço público que atende aos direitos da criança e da família; (IV) responde ao princípio de igualdade de oportunidade para as classes sociais, os sexos, as raças e os credos; (V) os critérios para admissão de crianças são democráticos, transparentes e não discriminatórios; (VI) o currículo respeita e valoriza as características culturais da população atendida; (VII) estimula a produção e o intercâmbio de conhecimentos; (VIII) prevê a gestão democrática dos equipamentos, com a participação das famílias e da comunidade. (NUNES, 2006, p. 2).

Em meio às informações abordadas até o momento, enfatizamos que a educação infantil se caracteriza como um direito da criança e dever do Estado, bem como espaços de cuidar e educar que visam a formação integral dos sujeitos. Dessa forma, a primeira etapa da educação básica passa a contemplar em suas políticas e práticas o reconhecimento das crianças enquanto sujeitos ativos que têm como direito vivenciar momentos de aprendizagens, interações, brincadeiras e trocas de experiências. Todavia, essas conquistas não se deram de maneira direta, já que na maioria dos municípios a educação infantil foi durante muito tempo assentada e orientada por serviços públicos e filantrópicos vinculados a práticas de assistência, sustentadas pelo serviço social. (KUHLMANN JR., 2015).

Dentre os processos de consolidação da educação infantil, Barreto (2003) salientou avanços em âmbito jurídico no que se refere aos direitos das crianças; contudo, também observou embates entre as áreas de gestão e financiamento das ações. Para Souza (2012), ainda existem algumas fragilidades com relação à institucionalização da educação infantil, como por exemplo, a falta de reconhecimento por parte de alguns governos de que ela é a primeira etapa da educação básica; permanências de concepções compensatórias; ausência da compreensão da criança como um sujeito de direitos; poucas iniciativas intersetoriais; pressões por resultados imediatos; despreparo de alguns setores da governabilidade, entre outros.

Nesse sentido, torna-se pertinente refletir sobre as formas, estratégias e concepções que envolvem a educação das crianças. Corroborando com Rocha (2003), salientamos que:

Pensar, analisar e perspectivar a educação de crianças em contextos institucionais educativos específicos exige que se retomem os diferentes níveis de análise sobre a criança, percebendo-se as diferentes dimensões de sua constituição e percebendo-a como um outro a ser ouvido e recebido. Em meu entender, esta complexidade representa para a Pedagogia a necessidade de percepção do sujeito-criança como objeto de sua ação, que não admite a transposição, de forma exclusiva e parcial, da visão de qualquer um dos recortes acima explicitados. Trata-se de orientar a ação pedagógica por olhares que contemplem sujeitos múltiplos e diversos, reconhecendo sobretudo a infância como "tempo de direitos". (ROCHA, 2003, p. 3). 
Diante de avanços, permanências e conquistas legais, a educação infantil conta com documentos oficiais, de nível nacional e local, que contemplam algumas especificidades, incluindo desde Referenciais e Diretrizes Curriculares até Orientações sobre convênios e Indicadores de qualidade. Além disso, após debates sobre propostas pedagógicas e suas particularidades, algumas estratégias de ensino e utilização de materiais também começam a integrar as discussões que envolvem a educação das crianças de zero a cinco anos de idade. Entre elas, destacamos a adoção de sistemas privados de ensino (SPE), por parte de algumas redes públicas municipais.

Pesquisas destacam que as relações do poder privado com os setores públicos podem remeter a uma dita eficiência e produtividade das ações do primeiro, em detrimento do Estado (ADRIÃO; PERONI, 2009; ADRIÃO; PINHEIRO, 2012; ARELARO, 2007). Adrião (2012) também levanta a discussão sobre as estratégias que podem gerar transformações das redes públicas de ensino em mercados educacionais. Sobre esse assunto, Adrião e Peroni (2009) destacam que:

\begin{abstract}
A esfera educacional responde às exigências [...] por meio da adoção de distintas políticas de convênio e parcerias: comprando material apostilado, adquirindo sistemas de gestão elaborados por instituições com ou sem fins lucrativos, ampliando as matrículas custeadas por recursos públicos em instituições privadas, além da terceirização de merendas e contratação de funcionários que não integram o quadro do magistério. As parcerias que incidem diretamente no desenho da política educacional, muitas vezes, partem de um diagnóstico de que os professores não são capazes de planejar suas tarefas e por isso devem receber "tudo pronto", [...]. (ADRIÃO; PERONI, 2009, p. 111).
\end{abstract}

Conforme os estudos, a adoção de sistemas privados de ensino é uma tendência que vem crescendo internacionalmente. Apple (1989), ao analisar o uso de "pacotes de material curricular" em escolas dos Estados Unidos da América, chama atenção para os procedimentos de controle técnico, já que os materiais apresentam um conjunto de objetivos, mecanismos de avaliação e: “[...] não apenas especifica quase tudo o que um professor precisa saber, dizer e fazer, mas em geral fornece um esboço de quais seriam respostas apropriadas dos alunos a esses elementos." (APPLE, 1989, p. 159). Tendo em vista tal constatação, o autor discute sobre o procedimento de desqualificação do processo educacional e de seus sujeitos; pois ações como planejamento e elaboração do currículo, estratégias de ensino para grupos e indivíduos específicos, dentre outras atividades docentes, não são mais "necessárias", já que os materiais delimitam todas as práticas, metodologias e avaliações, restando à/ao docente a execução do trabalho. 
Esses apontamentos sobre a utilização dos materiais apostilados suscitam problematizações referentes à padronização das ações, metodologias e avaliações.

[...] a adoção de apostilas, introduzidas precocemente como cartilhas a crianças pequenas, pode por em risco a constituição de uma ainda frágil identidade pedagógica da EI brasileira. Ou seja, se é sabido que a educação das crianças em creches e préescolas como um direito é conquista recente, também é sabido que o trabalho pedagógico nestes espaços educativos ainda oscila entre dois extremos: o "cuidar" e o "preparar para a alfabetização". Nesse contexto, a introdução de materiais diretivos, pré-definidos e padronizados, tende a estimular ainda mais o segundo extremo, levando professores a organizarem o tempo de permanência das crianças em creches e pré-escolas em função das atividades contidas nas apostilas [...]. (CORREA; ADRIÃO, 2014, p. 36-37).

Em meio ao debate sobre a padronização, vale salientar as questões sobre a autonomia das/dos profissionais na elaboração e no desenvolvimento das propostas cotidianas. Alguns SPE apresentam na divulgação de seus materiais a possibilidade de autonomia em âmbito da gestão e da área pedagógica. Porém, Britto (2011) elencou esse aspecto como uma das críticas sobre a adoção dos sistemas apostilados pelo fato de que, em alguns casos, as/os docentes: “[...] não são consultados sobre o material que deverão utilizar em sala de aula e passam a ficar presos a um rígido roteiro, transformando-se em meros aplicadores do material didático.” (BRITTO, 2011, p. 15). Por outro lado, a mesma autora relata a recepção positiva das/dos gestoras/es e das famílias sobre a admissão desses sistemas, principalmente, por contarem com objetivos de aprendizagens e sequências didáticas explicitadas.

Adrião, Damaso e Galzerano (2013), ao estudarem a expansão da adoção dos SPE nos municípios paulistas, constataram, ao entrevistar algumas/alguns docentes da educação infantil, que se caso as/os mesmas/os pudessem optar por permanecer ou suspender a utilização das apostilas, $69 \%$ escolheriam a primeira opção e apenas $24 \%$ interromperiam o uso do material. Ao mesmo passo que $91 \%$ declarou que o material precisa ser complementado, fato que questiona a ideia de qualidade. Tais apontamentos remetem a complexidade do assunto, visto que, mesmo com a padronização, a possibilidade de diminuição da autonomia e a necessidade de complementação, as/os profissionais optam pela manutenção da utilização do material. Sobre esse assunto, destacamos as reflexões de Silveira e Mizuki (2011), ao tratarem sobre a restrição da autonomia e suas possíveis consequências:

A restrição à autonomia da escola e do professor pode torná-lo dependente do material. Além disso, o método pedagógico utilizado pelo "sistema de ensino privado" pode não ser a concepção pela qual o professor se identifica, tornando-o um mero executor de uma proposta, ou seja, simplesmente um objeto do processo educativo, retirando-lhe a especificidade de sua função, de ser sujeito/ator desse processo, com a capacidade de planejar e refletir sobre a sua ação. (SILVEIRA; MIZUKI, 2011, p. 86). 
Para Silveira e Mizuki (2011), a utilização do material padronizado retira a possibilidade de autonomia da unidade educativa e das/dos professoras/es, restringindo o princípio da gestão democrática, assim como da ampliação das concepções pedagógicas. Além disso, a fundamentação jurídica para a aquisição de sistemas privados de ensino está mais ancorada em questões administrativas do que na legislação educacional vigente. Conforme Adrião et al. (2012, p. 537): “[...] as atuais relações entre as esferas públicas e privadas no campo da educação representam um movimento em direção a sua privatização". A partir do aumento da adoção de SPE, pesquisas sinalizam que essas medidas podem ser atribuídas às demandas de atendimentos e propostas atreladas às barreiras de cunho técnico, orçamentário e político. (ADRIÃO; DAMASO，2012; ADRIÃO; DAMASO; GALZERANO，2013; CORREA; ADRIÃO, 2014, entre outros).

Portanto, o processo de adesão dos SPE não pode se dar de forma aleatória, sem reflexões sobre as suas implicações, pois:

Pensar e administrar a educação pública sob ótica da esfera privada e nesse caso submetida aos interesses da acumulação do capital pressupõe transferir a educação de seu espaço principal - o campo da política, para a esfera do mercado submetendo seus processos e fins a interesses privados. (ADRIÃO; DAMASO, 2012, p. 6).

Adrião et al. (2009) explanam sobre a necessidade de análises das ações dos SPE, principalmente, por conta da falta de controle social ou técnico; fragilidade conceitual e pedagógica dos materiais e serviços comprados; vinculação do direito à qualidade de ensino submetida à lógica do lucro e padronização/homogeneização de conteúdos e currículos escolares, entre outros. Conforme Nascimento (2012), a admissão desses sistemas foi iniciada nas unidades privadas de ensino e atualmente as redes públicas também vêm aderindo com a justificativa de conquistar uma dita "qualidade de ensino".

Assim, ao mesmo tempo em que os municípios se municiavam de assessorias, planos de formação de professores, nova organização do sistema educativo próprio e das políticas municipais, em resposta às determinações legais, tomaram contato com os SPE para a educação básica, que acenavam com uma suposta garantia de qualidade, assegurada pelo próprio nome da empresa, sua grife. A eficiência desses materiais parecia comprovada pelo sucesso das escolas (privadas) que os adotavam e, nessa linha, começaram a ser comercializados também nas redes públicas de educação. (NASCIMENTO, 2012, p. 63).

Além do número expressivo de adesão aos SPE, Adrião e Damaso (2012, p. 5) também apontam para a permanência destes, ou seja: "[...] é possível perceber que o sistema privado uma vez adotado, tende a permanecer como política educacional.” Em meio aos movimentos de adoção e trocas dos SPE, Adrião (2012) observou que são firmadas novas parcerias e um conjunto se encerra, porém há um aumento constante no número de contratos. 
Percebe-se uma dinâmica irregular na adoção de "sistemas privados de ensino": há uma variação anual no conjunto de novas parcerias que se iniciam e no conjunto de parcerias que se encerram, porém mantendo uma tendência de crescimento constante no número de contratos anualmente assumidos pelas prefeituras. (ADRIÃO, 2012, p. 79).

Em face dessas constatações, múltiplas questões podem ser levantadas, como por exemplo: a inserção do poder privado em âmbitos públicos (ADRIÃO; PERONI, 2009; ADRIÃO; PINHEIRO, 2012); o financiamento da educação; as maneiras como as empresas contemplam as orientações de nível local e federal no que se refere à formação integral das crianças; as formas e motivos para a aquisição desses sistemas, considerando as possíveis diferenças existentes entre os materiais que são produzidos para as unidades públicas e as privadas (BRITO, 2007; NASCIMENTO, 2012); os debates sobre qualidade na educação infantil; entre outros aspectos que envolvem a gestão e as políticas educacionais.

Sobre a qualidade dos materiais dos SPE, Correa e Adrião (2014), ao analisarem as partes sobre linguagem, matemática e identidades em duas apostilas, constataram um viés de atividades direcionadas à antecipação para o ensino fundamental, as quais em muitas passagens vêm ao encontro das disposições das Diretrizes Curriculares Nacionais para a Educação Infantil (DCNEI /2010), ou seja, reforçam práticas de cópias, exercícios mecânicos e repetições, que são indicadas enquanto ações a serem evitadas. Com relação a esse assunto, Nascimento (2012, p. 74) apresenta que:

Há uma evidente discrepância nas concepções de infância e de educação infantil entre as orientações do MEC e os conteúdos das apostilas, ainda que não reconhecida pelos dirigentes nas entrevistas realizadas, o que parece indicar a ausência de uma avaliação pedagógica mais detalhada do material por ocasião da contratação do SPE.

Nessa direção, Correa e Adrião (2014) abordam sobre a preocupação das/dos gestoras/es no sentido de buscarem novas estratégias, contudo,

[...] mesmo considerando legítima a preocupação dos gestores que adotam este tipo de material no sentido de tentar assegurar uma mesma qualidade de educação para todas crianças na pré-escola, entendemos ser falaciosa a adoção de apostilas como meio de se chegar a esse objetivo, pois compreendemos que educação com qualidade para todos precisa respeitar diferenças de tempos, de ritmos e de interesses, especialmente em se tratando de crianças pequenas. (CORREA; ADRIÃO, 2014, p. 393).

As referidas pesquisadoras também apontam que os conteúdos e as formas das apostilas não favorecem as brincadeiras, a autonomia intelectual e nem as interações, elementos que são destacados nos documentos que visam subsidiar as ações na primeira etapa da educação básica.

A respeito das ações a serem desenvolvidas na educação infantil, Ostetto (2012) ressalta a importância de considerar os contextos educativos, escutar as crianças, bem como 
proporcionar situações desafiadoras e significativas. Ainda em relação às ações do cotidiano da educação infantil, cabe citar as contribuições de Nunes (2006), que afirma:

Não se trata, portanto, de atingir uma homogeneização abstrata dos fazeres pedagógicos, mas sim uma integração efetiva entre um projeto mais amplo, que propõe caminhos e estratégias, e as restrições concretas que devem ser superadas pouco a pouco, através do confronto entre as metas planejadas e as limitações objetivas de natureza política, administrativa e material que se refletem no dia a dia [...]. (NUNES, 2006, p. 4).

Assim, fica evidente a importância das interações e do desenvolvimento de ações intencionais e contextualizadas, tema que também pode ser abordado nos cursos de formação inicial e continuada. A respeito da oferta de formação continuada por parte dos SPE, estudos enfatizam que esses momentos são dedicados prioritariamente aos conteúdos e treinamentos para a utilização das apostilas, ou seja, limitados aos materiais que já estão postos (NASCIMENTO, 2012; CORREA; ADRIÃO, 2014; CARVALHO, 2018). Isto posto, caso determinadas questões não estejam contempladas nas apostilas, existem grandes possibilidades de permanecerem silenciadas no âmbito da formação continuada direcionada. Tendo em vista o papel fundamental que esses momentos ocupam, vale atentar para a seleção dos conteúdos e atividades elencados como relevantes para os SPE.

Embora com limitações pontuadas, os sistemas privados de ensino cada dia mais passam a circular os diferentes ambientes educacionais, tornando-se, portanto, pertinente investigar em que medida esses materiais possibilitam o protagonismo das/dos profissionais perante as ações, bem como as suas relações com os cotidianos das crianças e a formação integral delas (já que um número expressivo frequenta as unidades de educação infantil e passa boa parcela do tempo nesses espaços, vivenciando múltiplas experiências).

Partindo desse pressuposto, ressaltamos a importância da formação integral das crianças. Isto é: aspectos cognitivos, afetivos, motores, múltiplas linguagens, processo de construção das identidades e autoestimas precisam ser considerados nas unidades de educação infantil. Em acordo com pesquisas, consideramos que esses elementos também envolvem o reconhecimento, o respeito e a valorização da diversidade étnico-racial (CAVALLEIRO, 2015; DIAS, 2007; OLIVEIRA, 2004; CARVALHO, 2013).

Nessa direção, apontamos os estudos de Gonçalves e Silva (2007), no sentido de potencializar a importância da compreensão das relações raciais brasileiras. $\mathrm{O}$ entendimento das especificidades dessas relações deve remeter a problematizações no âmbito do trabalho pedagógico, envolvendo debates sobre a quantidade e a qualidade das propostas e concluindo que apenas a realização de um projeto isolado não será suficiente para o cumprimento do artigo 
26-A da LDB, que trata sobre a obrigatoriedade do ensino de história e cultura africana e afrobrasileira em todas as instituições de ensino.

Dessa forma, após conhecer alguns aspectos da complexidade que envolve a adoção de SPE, passamos para as análises dos materiais com foco na promoção da igualdade racial.

\section{Promoção da igualdade racial na educação infantil: analisando os materiais}

A literatura da área (GOMES, 2012; MARÇAL, 2011; SILVA, 2008) aponta que as relações raciais no Brasil são permeadas pelo mito da democracia racial, o qual rejeita a existência do racismo e das situações de preconceitos e discriminação em meios virtuais e presenciais.

Portanto, interpretamos que as relações sociais brasileiras são marcadas pelas desigualdades étnico-raciais, as quais se redesenham e reestruturam de diferentes formas e são intensificadas por meio da reprodução do ideal do branco como norma, do preconceito de marca, dos silêncios, entre outros aspectos que caracterizam, assim, o racismo à brasileira. Esse conceito, enunciado por Telles (2003), envolve a ênfase para as particularidades das relações raciais no Brasil, que são marcadas por serem sutis, manifestando-se, na maior parte das vezes, de forma implícita, gerando, inclusive, por parte de algumas pessoas, dúvidas sobre a existência do racismo e de preconceitos. Tal contexto favorece a manutenção das assimetrias raciais. Conforme apresenta Paixão (2013, p. 133-134):

[...] Os brancos entrariam nessa relação na condição de polo dominante e enquanto tal
interagiriam com os demais grupos reservando-se ao direito de saber de que forma
essa interação iria ocorrer. Sabendo-se superiores aos negros (em termos econômicos,
poder e de prestigio social), os brancos poderiam se abrir intermitentemente para
relações desinteressadas com aquelas pessoas que afinal de contas subordinariam. No
outro polo se exigiria que os negros tivessem um comportamento complacente para
com tal padrão. Na medida em que esses grupos não reivindicassem igualdade, mais
uma vez em termos econômicos, poder e de prestigio social, as relações entre ambos
os grupos poderiam transcorrer de forma amistosa nos momentos específicos das
festividades, do lazer e da religião (as áreas moles do contato racial). Ou seja, as
assimetrias é o preço que se paga pela paz. Assim, no interior desse ponto de vista,
são as disparidades raciais que garantem a qualidade dos modos de interação entre
brancos e negros no Brasil. [...], esse é o segredo do racismo à brasileira.

Segundo Telles (2003), umas das questões-chave nesses debates diz respeito aos posicionamentos e tratamentos diferenciados considerando as relações raciais na perspectiva horizontal e vertical. A primeira é caracterizada pelas relações no âmbito das afetividades; já a segunda abrange as ocupações nos cargos e espaços. Dessa forma, o autor chama atenção para a complexidade das relações raciais brasileiras, nas quais as relações horizontais podem ser aceitas com mais facilidade, porém as verticais geram mais preconceitos e questionamentos, 
visto que põem em voga o debate sobre os privilégios dos brancos nos âmbitos material e simbólico. Ambos os casos carregam complexidades em diferentes espaços e situações.

Observamos que tais questões também estão presentes nas dez apostilas analisadas, pois ao mesmo passo em que não há uma disseminação explícita de estereótipos (principalmente no que se refere a vestimentas e condições de representação inferiorizadas), há uma reprodução implícita no que diz respeito às ocupações em diferentes cargos e profissões.

Para a coleta de dados, realizamos análises de conteúdo a partir dos estudos de Rosemberg (1981), que propõe que o processo de análise de conteúdo consiste em:

[...] categorizar "cortes" efetuados no fluxo contínuo da mensagem. Como escolher os "cortes" (unidade de análise) e como caracterizá-los (categorias, unidades de contexto e de enumeração) só pode ser convenientemente respondido através da integração entre objeto de estudo e material a ser analisado. É assim que a elaboração do instrumento é um constante ir e vir entre os objetivos teóricos e o suporte empírico escolhido (ROSEMBERG, 1981, p. 70).

Dessa maneira, a análise de conteúdo:

1) constitui apenas um procedimento (ou um conjunto de procedimentos) e não um objeto de estudo ou uma teoria;

2) constitui um procedimento metodológico que tem estado a serviço de objetos de estudo ou de teorias;

3) constitui um procedimento metodológico dependente de objetos de estudo e teorias (ROSEMBERG, 1981, p. 74).

Nessa direção, Rosemberg (1981, p. 75) ainda aponta que a análise de conteúdo: “[...] pode se distribuir entre a definição do objeto de estudos e a coleta de dados; ela pode fusionar a coleta e a interpretação dos dados. Como ela pode, também, regulamentar o processo de coleta de dados".

Passando para os dados das apostilas, realçamos que uma das ilustrações presente na coleção editorial é significativa para a nossa análise, pois representa um homem negro e outro branco exercendo a mesma função, o que pode gerar interpretações referentes a uma certa igualdade nas representações. Entretanto, um dos pontos que chama atenção é o fato de que duas mulheres brancas estão nas condições de clientes e essa mesma ação não ocorre entre personagens negras ou entre brancas e negras. A partir daí, pode-se inferir que o poder aquisitivo está atrelado às/aos brancas/os, sendo aceitável a representação de brancos e negros em uma mesma ação, porém com destaque para os primeiros.

Em todos os livros, alguns de forma mais enfática e outros de maneira mais pontual, é possível identificar as interações entre crianças que foram heteroclassificadas, segundo 
raça/cor ${ }^{3}$, em diferentes categorias; isto é, existe a representação de relações horizontais entre brancas e negras. Estas se dão em todas as coleções. Contudo, vale destacar que a maior parte da amostra é composta por personagens brancas, conforme é possível verificar no Gráfico 1:

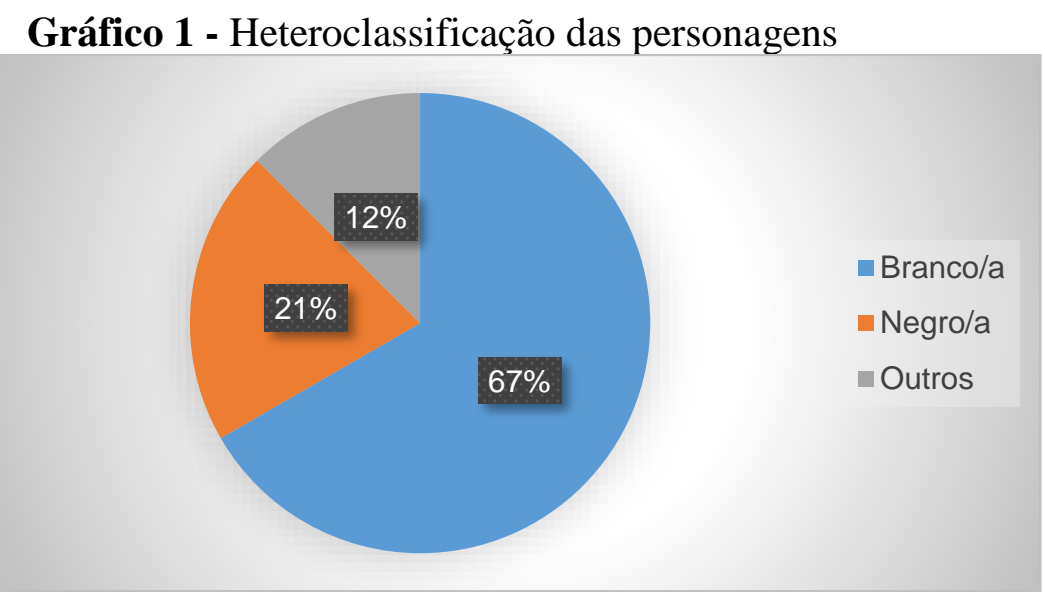

Fonte: A autora (2021).

A partir dos dados, verificamos que a representação do branco como norma da humanidade é preponderante nos livros didáticos de todas as coleções. Assim, identificamos que uma das estratégias dos SPE é a organização dos materiais contando com representação de poucas personagens pretas e pardas imersas a uma maioria branca. Fato que contribui para que a forma de distribuição desproporcional de personagens, segundo raça/cor, não seja evidenciada.

Outras imagens retratam aspectos que remetem às relações raciais verticais. Essas são evidentes em passagens que retratam a intelectualidade, as quais trazem apenas homens brancos. Compreendemos tal questão enquanto desigualdades nas representações das relações raciais de forma horizontal, pois envolvem poder. Isto é peculiar à amostra.

Ainda sobre esse assunto, vale ressaltar que corroboramos com a importância das personalidades enfatizadas, todavia, torna-se evidente que a ausência de negras/os demarca a intensidade das desigualdades raciais. A frequência de mulheres com o referido destaque também não foi significativa, entretanto, considerando algumas imagens é possível aferir que estas aparecem em funções atribuídas à produção de conhecimento.

Nessa direção, remetemo-nos para a não neutralidade no processo de escolha das imagens e dos textos, sendo possível inferir que este material reproduz o ideal de que a intelectualidade tem raça/cor, o que reforça as disparidades e as relações de desigualdade de tal

\footnotetext{
${ }^{3}$ Seguimos as categorias do Instituto Brasileiro de Geografia e Estatística (IBGE/2010), a saber: branca, preta, parda, indígena, amarela e outra. Cabe pontuar que com base nos estudos do movimento negro e pesquisadores/as da área Paixão e Carvano (2007), os dados da categoria negra são elaborados a partir da junção dos índices de pretas e pardas.
} 
forma que a produção do conhecimento está atrelada de forma frequente e direta ao homem branco. Já ao homem negro, são delegadas apenas funções que envolvem habilidade esportivas.

Não vinculamos a representação de negras/os aos esportes enquanto algo plenamente negativo, contudo, discordamos com a apresentação exclusiva desses personagens a essas ações, a qual os reduz e os limita a isso. Fato que, mesmo reconhecendo que o futebol é algo marcante na sociedade brasileira, categorizamos como uma reprodução estereotipada sobre as possibilidades de ocupações em determinados cargos, ou seja, retratos das relações raciais verticais.

Tal divisão é complexa, pois reproduz o ideal de que negras/os têm destaque apenas nas habilidades físicas e brancas/os são responsáveis pela ampliação dos conhecimentos. Argumento prejudicial, já que este foi e ainda é citado de diferentes formas em falas e atitudes racistas, contribuindo para a redução das perspectivas dos sujeitos, bem como para a propagação de preconceitos que atrelam homens e mulheres negras apenas ao corpo em detrimento da intelectualidade.

O mesmo movimento ocorre no que se refere às representações das/os professoras/es. Dos oito, apenas dois são homens negros. Sobre as formas e interações dos personagens, verificamos que os professores brancos explicitamente emitem falas, diferentemente do professor negro. Assim, os dois professores brancos têm ações mais elaboradas do que o professor negro.

Em relação às professoras, constatamos a presença exclusiva de mulheres brancas como professoras em destaque, contudo, nenhuma tem fala notória. Isto é, o direito à fala está vinculado aos professores do gênero masculino. Em todas as coleções, as representações de docentes seguem a mesma dinâmica: evidenciam personagens do sexo feminino, contudo, sem narrações.

Visto que homens brancos e negros e mulheres brancas foram representados/as em diferentes atividades, é evidente a ausência e a desvalorização das mulheres negras. No que se refere a profissões, elas não contam com frequências significativas sendo possível destacar apenas a mulher negra com vestimentas que remetem a funções na área da saúde. Focando na profissão docente, tal inexistência se torna ainda mais complexa ao considerarmos que, conforme Nunes (2012), grande parcela de professoras negras atua nas unidades da primeira etapa da educação básica. Portanto, essa ausência na representação de determinadas docentes não é favorável, principalmente tendo em vista que, no contexto das instituições de educação infantil, as/os professoras/es são referências importantes para as crianças. 
Em suma, considerando a estratégia apontada anteriormente, a relembrar: representação de uma ou duas personagens negras juntamente com uma maioria branca, analisamos que a nossa amostra apresenta maiores complexidades no que se refere às relações raciais de forma vertical do que horizontal, retratando, portanto, semelhanças com as relações sociais.

\section{Considerações finais}

No decorrer da presente produção, debatemos aspectos relacionados às políticas para educação infantil com ênfase nos aspectos que envolvem a adoção de sistemas privados de ensino. Estes são reconhecidos por ofertarem um material de qualidade, bem como anunciam o cumprimento das disposições das normativas nacionais, fato que nos impulsionou a verificar os aspectos dispostos no artigo 26-A da LDB, principalmente no que se refere às imagens.

A amostra retrata uma desproporção na quantidade de personagens brancas e negras, sendo que as primeiras são apresentadas de forma mais recorrente e as negras, em muitos casos, apenas compõem as imagens sem destaques. Considerando as representações das relações raciais na perspectiva horizontal (relações afetivas) e vertical (que envolvem disputa por poder), verificamos lacunas e limitações nas relações verticais, em especial as atreladas à intelectualidade.

Tendo em vista as informações detalhadas ao longo dessa produção, salientamos a relevância das reflexões sobre a adesão dos SPE na educação infantil, enfatizando as particularidades e especificidades da etapa, bem como a necessidade de análises dos materiais que, ponderando o nosso recorte, apresentaram posicionamentos e tratamentos diferenciados que precisam ser revistos em prol da importância da promoção da igualdade racial.

\section{Referências}

ADRIÃO T.; PERONI,V. A educação pública e sua relação com o setor privado: Implicações para a democracia educacional. Retratos da Escola, Brasília, v. 3, n. 4, p. 107-116, jan./jun. 2009.

ADRIÃO, T. et al. As parcerias entre prefeituras paulistas e o setor privado na política educacional: Expressão de simbiose? Educ. Soc., Campinas, v. 33, n. 119, p. 533-549, abr./jun. 2012.

ADRIÃO, T.; BORGHI, R.; DOMICIANO, C. A. Educação infantil, ensino fundamental: inúmeras tendências de privatização. Retratos da Escola, Brasília, v. 4, n. 7, p. 285-298, jul./dez. 2010. 
ADRIÃO, T.; DAMASO, A. Indicações sobre o crescimento da oferta de sistemas privados de ensino no estado de São Paulo. In: ENCONTRO NACIONAL DE DIDÁTICA E PRÁTICAS DE ENSINO, 16., 2012, Campinas. Anais... Campinas: Unicamp, 2012.

ADRIÃO, T.; DAMASO, A.; GALZERANO, L. A adoção de sistemas privados de ensino em escolas públicas de educação infantil: reflexões a partir do perfil dos professores. Rev. $e$ Curriculum, São Paulo, v. 2, n. 11, p. 434-460, ago. 2013.

ADRIÃO, T.; PINHEIRO, D. A presença do setor privado na gestão da educação pública: Refletindo sobre experiências brasileiras. Educação e Políticas em Debate, v. 1, n. 1, p. 55 66, jan./jul. 2012.

APPLE, M. Educação e poder. Porto Alegre: Artes Médicas, 1989.

ARELARO, L. Formulação e implementação das políticas públicas em educação e as parcerias público-privadas: impasse democrático ou mistificação política? Educação $e$ Sociedade, Campinas, v. 28, n. 100 - esp., p. 899-919, out. 2007.

BARRETO, A. A educação infantil no contexto das políticas públicas. Rev. Bras. de Educação, n. 24, p. 53-65, dez. 2003.

BRASIL. Constituição da República Federativa do Brasil. Brasília, 1988.

BRASIL. Lei de Diretrizes e Bases da Educação Nacional. Brasília: CNE, 1996.

BRASIL. Diretrizes curriculares nacionais para a educação das relações étnico-raciais e para o ensino de história e cultura africana e afro-brasileira. Brasília: CNE, 2004.

BRASIL. Diretrizes Curriculares Nacionais para a Educação Infantil. Brasília: MEC, 2010.

BRASIL. Educação Infantil e Práticas Promotoras de Igualdade Racial. Brasília: MEC, 2012.

BRITTO, T. F. O Livro Didático, o Mercado Editorial e os Sistemas de Ensino Apostilados. Centro de estudos da consultoria do Senado: Textos para discussão 92, jun. 2011.

CARVALHO, T. Políticas de promoção da igualdade racial na rede municipal de educação infantil de Florianópolis/SC. Dissertação (Mestrado em Educação) - Curitiba: Universidade Federal do Paraná, 2013.

CARVALHO, T. Diversidade étnico-racial na educação infantil: análises de um sistema privado de ensino adotado por uma rede pública municipal. Tese (Doutorado em Educação) Curitiba: Universidade Federal do Paraná, 2018.

CAVALLEIRO, E. Do silêncio do lar ao silêncio escolar: racismo, preconceito e discriminação na educação infantil. São Paulo: Contexto, 2015.

CORREA, B.; ADRIÃO, T. Reflexões sobre a adoção de sistemas privados de ensino em escolas municipais de educação infantil. In: ADRIÃ̃, T. et al. Sistemas de ensino privados 
na educação pública brasileira: consequências da mercantilização para o direito à educação. 2014.

DIAS, L. No fio do horizonte: educadoras da primeira infância e o combate ao racismo. Tese (Doutorado em Educação) - São Paulo: Universidade de São Paulo, 2007.

GOMES, N. Movimento Negro e Educação: Ressignificando e Politizando a Raça. Educ. Soc., Campinas, v. 33, n. 120, p. 727-744, jul./set. 2012.

GONÇALVES E SILVA, P. Aprender, ensinar e relações étnico-raciais no Brasil. Educação, Porto Alegre, ano XXX, n. 3, v. 63, p. 489-506, set./dez. 2007.

KUHLMANN JÚNIOR, M. Infância e educação infantil: uma abordagem histórica. Porto Alegre: Mediação, 2015.

MARÇAL, J. Política de Ação Afirmativa na Universidade Federal do Paraná e a Formação de Intelectuais Negros (as). Dissertação (Mestrado em Educação) - Curitiba: Universidade Federal do Paraná, 2011.

NASCIMENTO, M. As políticas públicas de educação infantil e a utilização de sistemas apostilados no cotidiano de creches e pré-escolas públicas. Rev. Bras. de Educação, v. 17 n. 49, p. 59-80, jan./abr. 2012.

NUNES, M. Educação Infantil: Instituições, Funções e Propostas. In: O cotidiano na Educação Infantil: Boletim 23. Ministério da Educação: Secretaria de Educação a Distância, nov. 2006.

NUNES, M. Histórias de Ébano: Professoras negras de educação infantil da cidade de São Paulo. Dissertação (Mestrado em educação) - São Paulo: Universidade de São Paulo, 2012.

OLIVEIRA, F. Um estudo sobre a creche: o que as práticas pedagógicas produzem e revelam sobre a questão racial? Dissertação (Mestrado em Educação) - São Carlos: UFSCar, 2004.

OSTETTO, L. Encontros e encantamentos na educação infantil. Campinas: Papirus, 2012.

PAIXÃO, M. 500 anos de solidão: estudos sobre desigualdades raciais no Brasil. Curitiba: Appris, 2013.

PAIXÃO, M.; CARVANO, L. Oficina de Indicadores Sociais (Ênfase em Relações Raciais). Rio de Janeiro: LAESER, 2007.

ROCHA, E. A função social das instituições de educação infantil. Revista Eletrônica Zero a Seis, Florianópolis, n. 7, jan./jun. 2003.

ROSEMBERG, F. Da intimidade aos quiprocós: uma discussão em torno da análise de conteúdo. Cadernos CERU, São Paulo, n. 16, p. 69-80, 1981.

ROSEMBERG, F. A criança pequena e o direito a creche no contexto dos debates sobre infâncias e relações raciais. In: BRASIL. Ministério da Educação. Educação Infantil, 
igualdade Racial e diversidade: Aspectos políticos, jurídicos, conceituais. Brasília: MEC, 2011.

SILVA, P. Racismo em livros didáticos: estudo sobre negros e brancos em livros de Língua Portuguesa. Belo Horizonte: Autêntica, 2008.

SILVEIRA, A.; MIZUKI, V. Sobre a legalidade da aquisição e uso dos "sistemas de ensino privados" na educação pública. Educação: teoria e prática, v. 21, n. 38, p. 79-97, out./dez. 2011.

SOUZA, G. Políticas para a Educação Infantil: Caminhos atuais. Palestra proferida no Seminário Internacional de Educação Infantil (Mesa redonda: Políticas para a Educação Infantil: Caminhos atuais), Florianópolis, Universidade Federal de Santa Catarina, 2012.

TELLES, E. Racismo à brasileira: uma nova perspectiva sociológica. Rio de Janeiro: Relumé Dumará/Fundação Ford, 2003. 